\title{
Competitividade no turismo: Uma comparação entre Brasil e Suíça ${ }^{i}$
}

\author{
Competitiveness in tourism: \\ A comparison between Brazil and Switzerland
}

\author{
La competitividad en el turismo: \\ Una comparación entre Brasil y Suiza
}

\section{Maria Gabriela Montanari ${ }^{1}$ Janaina de Moura Engracia Giraldi ${ }^{2}$}

\begin{abstract}
Resumo: Mesmo com a situação global instável, com a crise na zona do euro, o turismo mundial permaneceu forte e teve um crescimento positivo nos últimos anos. Além disso, essa atividade tem uma grande importância econômica e social que se reflete na sua capacidade de gerar emprego e renda. Dessa maneira, este artigo tem como objetivo analisar a competitividade do setor turístico no Brasil e na Suíça, comparando os dois países por meio dos fatores de competitividade identificados pelo índice Mundial de Competitividade em Turismo (Travel \& Tourism Competitiveness Index - TTCl). Fazendo essa comparação, foi possível perceber que a Suíça é muito mais desenvolvida que o Brasil nesse setor e possui, portanto, muito mais fontes de vantagens competitivas, das quais se destacam a sustentabilidade, a infraestrutura de transportes e os recursos humanos e culturais. O Brasil, por outro lado, tem como grande força os seus recursos naturais, o que não é suficiente para garantir um setor de turismo desenvolvido. Assim, foram obtidas informações que podem colaborar com o setor turístico e com os governos dos dois países para desenvolvimento estratégico de ações e reflexão teórica para pesquisas na área.
\end{abstract}

Palavras-chave: Turismo; Competitividade; Brasil; Suíça.

Abstract: Despite the unstable global situation and the crisis in the euro area, world tourism has remained strong and with a positive growth in the last years. Besides, this activity has a great economic and social importance which is reflected in its ability to generate jobs and income. Thus, this article aims to analyze the competitiveness of the tourism sector in Brazil and Switzerland, comparing the two countries through competitive factors identified by the World Competitiveness Index in Tourism (Travel \& Tourism Competitiveness Index - TTCI). Making this comparison, it was revealed that Switzerland is much more developed than Brazil in this sector and therefore has many more sources of competitive advantages, from which are highlighted sustainability, transportation infrastructure and human and cultural resources. On the other hand, Brazil has a great strength with its natural resources, which is not enough to guarantee a developed tourism sector. Thus, information was obtained that can collaborate with the tourism industry and the governments of both countries to develop strategic actions and for theoretical research in the area. Keywords: Tourism; Competitiveness; Brazil; Switzerland.

\footnotetext{
${ }^{1}$ Bacharel em Matemática Aplicada a Negócios pela Universidade de São Paulo. E-mail: mariagabrielamontanari@yahoo.com.br

2 Professora doutora do Dep. de Administração da FEA-RP/USP Universidade de São Paulo. E-mail: jgiraldi@usp.br
} 
Resumen: A pesar de la situación global inestable, con la crisis en la zona euro, el turismo mundial se ha mantenido fuerte y con positivo crecimiento en los últimos años. Además, esta actividad tiene una gran importancia económica y social que se refleja en su capacidad de generar empleo e ingresos. Por lo tanto, este artículo tiene como objetivo analizar la competitividad del sector de turismo en Brasil y Suiza. Se hizo la comparación de los dos países a través de factores de competencia identificados por el Índice de Competitividad Mundial del Turismo (Travel \& Tourism Competitiveness Index - TTCI). Con esta comparación, se reveló que Suiza es mucho más desarrollada que la de Brasil en este sector y por lo tanto tiene muchas más fuentes de ventajas competitivas, como lo más importante la sostenibilidad, la infraestructura de transporte y los recursos humanos y culturales. Brasil, por su parte, tiene una gran fuerza como sus recursos naturales, lo cual no es suficiente para garantizar un sector turístico desarrollado. Así, se obtuvo información que puede colaborar con la industria del turismo y los gobiernos de ambos países para desarrollar acciones estratégicas y para la investigación teórica en la zona.

Palabras clave: El turismo; Competitividad; Brasil; Suiza.

\section{INTRODUÇÃO}

Mesmo com a situação global instável, o setor de turismo mundial permaneceu forte e teve um crescimento positivo, mesmo que inicialmente menor do que o esperado em 2011 . 0 número chegadas de turistas internacionais aumentou cerca de $5 \%$ de janeiro a agosto de 2011, segundo a UNWTO e a Haver Analytics (WTTC, 2011a) e a OMT (Organização Mundial do Turismo). Esse crescimento deve-se a inúmeros fatores, como: atuação da globalização, inovação, facilidade da comunicação, investimento em transportes e aumento da necessidade de compartilhamento dos recursos ambientais (Clegg, Hardy \& Nord, 2004). Além disso, essa atividade tem uma grande importância econômica e social que se reflete na sua capacidade de gerar emprego e renda, já que engloba uma série de atividades interligadas: transporte, hospedagem, alimentação, entretenimento, entre outras (Ferreira, 2010).

Ainda pode-se dizer que o desenvolvimento no setor turístico pode ser traduzido em termos de vantagem competitiva, pois para uma se atividade se desenvolver e ser considerada bem sucedida em termos internacionais, o setor deve apresentar vantagem competitiva em relação aos melhores competidores do mundo (Porter, 1999). A competitividade do turismo foi definida por Hassan (2000, p.239-240) como "a capacidade do destino para criar e integrar valor agregado a produtos que mantenham seus recursos, mantendo a posição de mercado em relação aos seus concorrentes", depende de vários fatores e é elevada, porque esse setor já é uma das principais atividades econômicas em termos mundiais, o que faz com que cresça a quantidade de localidades que querem se desenvolver com a ajuda ou mesmo por meio dele, levando assim, a um aumento da competitividade (Valls, 1996).

O sucesso da posição estratégica de um destino turístico no mercado turístico internacional, seja cidade, região ou país, evoca um conjunto de decisões que representam uma fonte de vantagem competitiva sobre outros destinos concorrentes (Pike, 2008). Logo, é necessário que sejam criadas novas estratégias em termos nacionais e internacionais, e que sejam aperfeiçoadas as que já foram elaboradas. 
Para orientação e referência global da competitividade no setor, foi desenvolvido em 2009 pelo World Economic Forum (WEF) em parceria com instituições de vários países o Índice Mundial de Competitividade em Turismo do ano de 2009 (Travel \& Tourism Competitiveness Index - TTCI). Esse índice mediu e analisou os fatores determinantes para a competitividade no turismo em nível mundial, classificando os países de acordo com seu desempenho em relação a esses fatores (WEF, 2009). De acordo com o resultado do índice, o Brasil está na 5a posição na América, atrás dos seguintes colocados em ordem crescente: Canadá, Estados Unidos, Barbados e Costa Rica. Mundialmente, o Brasil está na 45a posição, sendo que avançou quatro posições desde o ano de 2008; mas ainda está distante da Suíça, primeira colocada do ranking (WEF, 2009). O TTCl está em sua terceira edição e é organizado pelo World Economic Forum, por meio de um relatório anual chamado The Travel and Tourism Competitiviness Report. $\mathrm{O}$ índice tem intuito de conhecer a realidade do setor turístico de cada país, aferindo os contextos relacionados aos negócios turísticos para ir ao encontro da melhoria da competitividade do turismo do país (WEF, 2009).

Dessa forma, esse artigo teve como objetivo principal uma comparação entre Brasil e Suíça (país mais bem colocado no índice), analisando os fatores de competitividade no turismo em cada país e identificando as suas deficiências e potencialidades. A comparação utilizou os fatores de competitividade em turismo identificados pelo Índice Mundial de Competitividade em Turismo, que foram estudados de forma geral e depois especificamente em cada um dos países, por meio das pontuações de Brasil e Suíça em cada fator e das informações encontradas na literatura.

\section{ÍNDICE MUNDIAL DE COMPETITIVIDADE EM TURISMO}

O Índice Mundial de Competitividade em Turismo (TTCl), que pode ser considerado um documento de extrema relevância quando se discute sobre a competitividade no turismo, identificou os 14 fatores determinantes para a competitividade no turismo (pontuados em cada país numa escala de 0 a 7, classificando cada um de acordo com essas pontuações) e analisou as possíveis fontes de vantagem competitiva no setor de viagens e turismo dos países do Índice. Esses 14 fatores foram agrupados em três pilares de competitividade:

- Sistema Regulamentador: inclui os fatores de regulamentações e leis políticas, sustentabilidade ambiental, segurança e seguridade, saúde e higiene e priorização do turismo e viagem.

- Infraestrutura e Meio-ambiente: tem os fatores de infraestrutura do transporte aéreo, infraestrutura do transporte público, infraestrutura do turismo, infraestrutura do ICT (internet) e preço competitivo em turismo e viagem.

- Recursos Humanos, Culturais e Naturais: inclui além dos recursos humanos, naturais e culturais a questão da afinidade pelo turismo e viagem.

É importante destacar aqui que cada um desses três pilares é calculado como uma média dos contextos que os compõem. O primeiro fator do Índice (regulamentações e leis políticas) 
mede o quanto o ambiente político causa de impacto sobre a atratividade e o desenvolvimento do turismo em cada país. Às vezes, uma política pode ser bem intencionada, mas não consegue o resultado esperado ou não consegue ser colocada em prática devido a burocracias, ou ainda depende de acordos com outros países. Ele é medido pelo relatório utilizando: a prevalência de propriedade estrangeira, direitos de propriedade, o impacto nos negócios de regras sobre o "FDI", as exigências de visto, abertura de acordos bilaterais de serviços aéreos, a transparência da política governamental, o tempo necessário para iniciar um negócio e o custo para abrir uma empresa (WEF, 2009). Essas regulamentações e leis políticas aparecem como barreiras à entrada de novos hotéis, companhias aéreas e agências de turismo, podendo prejudicar ou alavancar o desenvolvimento do setor turístico por meio de um ambiente político favorável ou desfavorável.

Quanto à sustentabilidade ambiental, pode-se afirmar que ela influencia não somente na escolha de um local de destino hoje, devido à importância da questão ambiental, mas é importante fundamentalmente para as escolhas futuras, sendo determinada pelos seguintes itens: rigor da legislação ambiental, execução de regulamentação ambiental, desenvolvimento sustentável do setor turístico, emissões de dióxido de carbono, concentração de material particulado, espécies ameaçadas e ratificação do Tratado Ambiental (WEF, 2009). Quando ela está relacionada ao turismo, ela transparece o desenvolvimento de estratégias, políticas e ações contínuas no setor visando à preservação ambiental e sua base e qualidade dependem da manutenção e desenvolvimento do setor (Cooperbom Turismo, 2008). Numa escala global, o desenvolvimento do turismo sustentável se tornou um objetivo estratégico importantíssimo (Hassan, 2000).

O contexto da segurança é crítico na questão da competitividade, porque os turistas não viajam para lugares com elevados índices de crime, violência e terrorismo, configurando, dessa maneira, provavelmente uma relação positiva com o desenvolvimento do turismo, isto é, quanto maior a segurança que uma localidade proporciona, maior o desenvolvimento (WEF, 2009). Ele é medido por meio dos seguintes indicadores: custos das empresas de terrorismo, confiabilidade dos serviços policiais, custos das empresas de criminalidade e violência e acidentes de viação (WEF, 2009). A saúde e a higiene também são relevantes, porque um turista precisa de condições mínimas para uma boa estadia, como água potável e saneamento, além de um sistema de saúde eficiente no local de destino caso ocorra uma doença ou um acidente (WEF, 2009).

No caso do turismo, há ainda o denominado turismo médico, que é uma busca por um tratamento específico em outro país especificamente na diferenciação para a escolha de um destino, pois ela inclui fatores como a busca por reduzir seus custos médicos, evitar longas filas de espera por cirurgia, obter um tratamento de qualidade, entre outros (Freitas, 2010). Para mensurar esse fator, o World Economic Forum utilizou: a densidade de médicos nas localidades, o acesso a saneamento básico, o acesso à água potável e a quantidade de leitos hospitalares.

A questão de priorizar o turismo também deve ser considerada, podendo esta ser desmembrada nas variáveis de acordo com o relatório do $\mathrm{TTCl}$ : priorização ao setor de viagens e 
turismo, priorização por parte do governo da indústria turística, gastos do governo em turismo, eficácia de marketing e branding para atrair turistas e participação em feiras turísticas (WEF, 2009). Quando esse setor se torna uma prioridade, isso é refletido em seu orçamento e em novos projetos, podendo atrair novos investimentos do setor privado (WEF, 2009).

Isso pode ficar bem claro no caso da Copa de 2014 no Brasil, em que o governo brasileiro passou a realizar grandes investimentos, implantar políticas, ações e projetos no setor do turismo, juntamente com o Ministério do Turismo. O governo reconheceu no evento uma oportunidade de desenvolvimento local e nacional de forma sustentável dos destinos turísticos escolhidos como sede, por meio da estruturação dessas localidades, para que estas atinjam um padrão de qualidade internacional e estimulem a permanência do turista antes, durante e depois do evento e se tornem fontes de renda e emprego para a população brasileira (Brasil, 2011).

Já a infraestrutura do transporte aéreo é proporcional à competitividade e atratividade de um país; quanto maior é a qualidade dessa estrutura, maior é a facilidade de acesso aos países e assim mais atrativo torna-se o setor e, portanto, mais desenvolvido. Pode ser medida considerando a infraestrutura do transporte aéreo, a qualidade dessa infraestrutura, os quilômetros percorridos nacionalmente, partidas de aviões a cada 1.000 habitantes, a densidade dos aeroportos, o número de companhias aéreas que operam nos aeroportos e a rede de transporte aéreo internacional (WEF, 2009).

A infraestrutura do transporte público envolve acesso aos meios de transporte, localização, qualidade de estradas; que são importantes para que o turista se desloque com facilidade para os destinos planejados dentro de um país ou de um país para outro e logo, são medidas do desenvolvimento do turismo. Mais especificamente, essa infraestrutura pode ser medida pela qualidade das estradas, qualidade da infraestrutura ferroviária, qualidade da infraestrutura portuária, qualidade da rede de transporte nacional e a densidade das estradas (WEF, 2009). Por fim, quando se fala de maneira geral sobre transportes e estrutura é preciso destacar que esse é um critério chave para a escolha do destino por parte do turista, pois a qualidade da experiência do transporte (segurança, conforto, rapidez, acesso facilitado) tornase uma parte importante da experiência do turista em si (Beni, 2001).

Há também a infraestrutura do turismo, que é relevante, pois considera a quantidade de hotéis, a disponibilidade de hotéis e a estrutura de sua rede, ou mais especificamente os números de quartos de hotel, a presença das principais companhias locadoras de carro e a quantidade de caixas eletrônicos que aceitam cartões Visa. Há ainda a infraestrutura do ICT, ou seja, da internet, que é um importante meio de divulgação e também é um atrativo quando o acesso a ela é fácil, sendo mensurada por: extensão do uso da internet comercial, número de usuários da internet, número de linhas telefônicas, quantidade de assinantes de banda larga de internet, quantidade de assinantes de internet móvel (WEF, 2009).

Outro fator é a competitividade do preço, pois um custo reduzido é um fator que atrai muitos turistas para as localidades. O preço no turismo depende da competitividade entre 
preços desse setor, das taxas de aeroportos, da paridade de poder de compra, da extensão e efeitos da tributação, dos níveis de preços do combustível (WEF, 2009).

A disponibilidade de recursos humanos relacionada à formação e à qualidade e quantidade de mão de obra também influencia no desenvolvimento do turismo. Ela está diretamente ligada à escolha do turista, que sempre busca conforto e bom atendimento. Além disso, a mão de obra (recurso humano) é importante num destino turístico porque gera muitos empregos (Aulicino, 1994). Esse fator está ligado aos fatores de produção do modelo o diamante.

O relatório do $\mathrm{TTCl}$ considera o fator de recursos humanos em fatores relacionados primeiramente à educação, que são: matrícula no ensino primário, matrícula no ensino secundário, qualidade do sistema educacional, disponibilidade local de pesquisa especializado e com treinamento e extensão de formação do pessoal, além de detalhar em fatores relacionados à disponibilidade de mão de obra qualificada: práticas de contratação e demissão, facilidade de contratação de mão de obra estrangeira, prevalência do HIV, impacto nas empresas de HIV/AIDS3 e expectativa de vida (WEF, 2009).

A afinidade pelo turismo é um fator que mede a extensão em que o país e a sociedade estão abertos aos visitantes e isso tem um impacto importante sobre a competitividade. Pode ser desmembrada em: abertura do turismo, atitude da população com os visitantes estrangeiros e extensão de viagens de negócios recomendada (WEF, 2009).

Os dois contextos finais elaborados pelo índice são os recursos naturais e os culturais. Em relação aos recursos naturais, quanto maior e mais fácil o acesso a eles maior é a vantagem competitiva, e na questão dos recursos culturais, eles são um atrativo e, portanto, uma fonte de vantagem competitiva (WEF, 2009). Eles podem ser mensurados pelos seguintes indicadores: número de sítios naturais que fazem parte do patrimônio mundial, áreas ambientais protegidas, qualidade do ambiente natural, total de espécies conhecidas, número de sítios culturais que fazem parte do patrimônio mundial, estádios esportivos, número de feiras e exposições internacionais e exportações de indústrias criativas (WEF, 2009).

Portanto, existem muitos aspectos a serem analisados, tanto no turismo brasileiro quanto no da Suíça, para que pontos fortes possam permanecer e pontos fracos possam ser melhorados. Este artigo pode auxiliar nesse aspecto, pois foi possível estudar os fatores determinantes da competitividade apontados pelo Índice para poder realizar a comparação entre os dois países.

\section{COMPETITIVIDADE DO TURISMO NA SUÍÇA}

Para compreender melhor os fatores de competitividade no turismo mais importantes para a economia da Suíça e compará-la com o Brasil, foram tomadas como referência as pontuações (que variam de 0 a 7) de ambos os países nos 14 contextos do $T T C l$ e suas respectivas posições em relação aos outros países do mundo nesses contextos. A comparação está resumida na Tabela 1: 
Tabela 1. Comparação entre Brasil e Suíça utilizando o Índice Mundial de Competitividade no Turismo de 2009.

\begin{tabular}{|l|r|r|r|r|}
\hline & \multicolumn{2}{|c|}{ Suíça } & \multicolumn{2}{|c|}{ Brasil } \\
\cline { 2 - 5 } & Posição & Pontuação & Posição & Pontuação \\
\hline 1. Regulamentações e Leis Políticas & 18 & 5,25 & 94 & 3,97 \\
\hline 2. Sustentabilidade Ambiental & 2 & 5,89 & 33 & 4,96 \\
\hline 3. Segurança e Seguridade & 8 & 6,4 & 130 & 3,36 \\
\hline 4. Saúde e Higiene & 13 & 6,62 & 80 & 4,2 \\
\hline 5. Priorização do Turismo e Viagem & 7 & 5,88 & 84 & 4,11 \\
\hline 6. Infraestrutura do Transporte Aéreo & 17 & 4,9 & 46 & 3,76 \\
\hline 7. Infraestrutura do Transporte Público & 1 & 6,58 & 110 & 2,59 \\
\hline 8. Infraestrutura do Turismo & 7 & 6,6 & 45 & 4 \\
\hline 9. Infraestrutura do ICT & 3 & 5,78 & 60 & 3,06 \\
\hline 10. Preço competitivo em Turismo e Viagem & 123 & 3,59 & 91 & 4,24 \\
\hline 11. Recursos Humanos & 4 & 6,15 & 55 & 5,17 \\
\hline 12. Afinidade pelo Turismo e Viagem & 34 & 5,12 & 108 & 4,41 \\
\hline 13. Recursos Naturais & 15 & 4,88 & 2 & 6,37 \\
\hline 14. Recursos Culturais & 3 & 6,02 & 14 & 5,64 \\
\hline
\end{tabular}

Fonte: Adaptado de WEF-2009.

Após a análise cuidadosa dessa tabela, pode-se explicar com clareza como se configura a competitividade no turismo na Suíça e o motivo desse país estar tão à frente do Brasil no ranking mundial de competitividade em turismo. Primeiramente, a Suíça é um país pequeno, mas rico e com uma longa tradição em hospedar turistas (Weiemair \& Bieger, 2005). Até o século XVIII o país não era um destino, mas uma passagem obrigatória no centro da Europa, conhecido pelas suas universidades e movimentos religiosos nas cidades da Basileia e de Genebra. Porém, é no século XIX que o turismo passa a se desenvolver e se estruturar realmente, na região dos Alpes.

Com o passar do tempo, tanto o turismo doméstico como internacional tornaram-se muito importantes na economia da Suíça (STF, 2007). Os gastos dos visitantes domésticos e internacionais criaram volume de negócios e valor adicionado para muitas grandes empresas em diversos setores da economia (OCDE, 2000). Em 2006, o setor turístico estava em quarto lugar na balança de exportação nacional de Suíça com uma participação de 6,2 \% no Produto Interno Bruto (Serquet \& Rebetez, 2011). A importância desse setor é evidenciada pela intensidade do turismo nessa região, que é medida pelo número de turistas por população nativa ou em termos de receitas de turismo por população (Weiemair \& Bieger, 2005), e é muito maior que a do Brasil. Essa intensidade tem uma relação clara e positiva com o PIB per capita (WEF, 2009), o que mostra que o turismo é um fenômeno econômico relevante e tem uma relação direta com o desenvolvimento econômico dos países.

Deve-se ressaltar que este país foi um dos primeiros a desenvolver turismo como uma indústria essencial, e para muitos viajantes, isso é importante ao escolher o destino no exterior 
para as suas férias (Tajeddini, 2010). Isso significa que a Suíça foi um dos países pioneiros a priorizar e investir no turismo e que essa priorização do setor pelo país é importante para muitas pessoas no momento de escolher seu destino, tornando-se dessa forma uma fonte importantíssima de vantagem competitiva. Este pode ser um dos motivos pelos quais a Suíça ocupa o sétimo lugar no ranking do pilar que trata da priorização do turismo, o que pode ser observado pela Tabela 1. Nesse aspecto, essa nação é mais desenvolvida que o Brasil, que ocupa apenas a octogésima quarta posição.

Em sua totalidade, o país pode ser dividido em treze regiões turísticas, nas quais estão as regiões de Zurique, de Genebra e a região central (STF, 2007). Os principais destinos são as montanhas (tanto no inverno quanto no verão) e as cidades suíças, como Zurique e Genebra (Perch-Nielsen, Seasartic \& Stucki, 2010). Os famosos Alpes suíços são um dos lugares mais tradicionais do turismo mundial e constituem um fundamental componente da economia da Suíça (Serquet \& Rebetez, 2011).

É importante lembrar aqui que a competitividade é a chave para o sucesso ou o fracasso de um destino (BAK, 2012) e que a região dos Alpes é um recurso natural poderoso, que atrai muitos turistas e é, portanto, um fator de competitividade relevante no turismo suíço. Em outras palavras, as montanhas e os Alpes são muito dependentes da renda gerada pelo turismo, ocupando um papel importante na cadeia de geração de valor desse setor (STF, 2007). Além disso, o turismo nessa área montanhosa, assim como no restante do país gera muitos empregos (STF, 2007). Consequentemente gera-se também renda e desenvolvimento para todo o país.

Contudo, essa região dos Alpes é competitiva não somente devido ao recurso natural em si e à qualidade do ambiente natural, mas também devido às atrações que eles proporcionam, como: os passeios de skis e snowboards, os esportes de aventura, os hotéis de luxo e sua oferta diversificada (BAK, 2012). Nos Alpes, a demanda turística é determinada por fatores como clima, paisagem, acesso a lagos, preços, entre outros (Serquet \& Rebetez, 2011).

Há na Suíça, além dos Alpes, muitos parques e sítios naturais como o Parque Natural Gantrisch, o Parque Natural Binntal, o Parque Natural Pfyn-Finges, o Parque Natural Doubs, Biosfera Val Müstair. Este último é um sítio natural, biosfera reconhecida pela UNESCO e o terceiro é caracterizado como uma região com extraordinária variedade de espécies (Suíça, 2012a).

As informações relatadas mostram a força dos recursos naturais na Suíça apesar de sua pequena extensão e justificam a posição entre os 15 melhores países nessa categoria no Índice Mundial de Competitividade em Turismo de 2009, que considera a qualidade do ambiente natural, a quantidade de espécies conhecidas, o número de sítios e patrimônios naturais e a quantidade de áreas protegidas, que no país representa uma grande porcentagem das áreas terrestres (WEF, 2009). Esse imenso patrimônio natural do país é reforçado por um grande foco na questão da sustentabilidade ambiental, com uma legislação que visa desenvolver o setor de maneira sustentável, levando a Suíça diretamente ao segundo lugar no ranking de sustentabilidade ambiental, trinta e uma posições a frente do Brasil no TTCI (WEF, 2009). 
Outro aspecto que chama a atenção dos turistas são as atrações históricas e culturais como, por exemplo, o famoso queijo suíço, cuja fabricação pode ser visitada por turistas na AOC Queijaria de Demonstração de Emmental (Suíça, 2012c). Há ainda muitas abadias e igrejas, que fazem parte do patrimônio do país, como a Mogno - Igreja da Montanha de Mario Botta e a Igreja da Abadia de Romainmôtier, construída a mais de 1000 anos. O país também é sede do Museu Olímpico, que conta a história do segundo maior evento do mundo (os jogos olímpicos), do Museu Nacional Suíço em Zurique, do Museu da Fotografia, do Museu de Arte de Genebra (que contém mais de 7000 peças desde artefatos pré-históricos até artefatos modernos), do Acervo Rosengard-Klee, Picasso, Césanne (Suíça, 2012c). Para completar esse patrimônio da humanidade existem ainda os palácios e castelos, como o castelo de Chillon e o castelo e a cidade medieval de Gruyères (Suíça, 2012c).

Na questão cultural ainda é possível afirmar que Suíça não é apenas um destino voltado para o lazer, mas também é um local de turismo voltado a negócios, com muitas feiras internacionais e exposições (WEF, 2009). Essa abundância de feiras, castelos, museus, exposições é traduzida em um terceiro lugar no pilar de recursos culturais, com uma pontuação alta de 6,02, acima dos 5,64 do Brasil, que aparece na décima quarta posição (WEF, 2009).

Junto com os recursos naturais e culturais estão os recursos humanos, que são tão importantes quanto os dois anteriores. A Suíça possui um sistema educacional qualificado, além de ter uma grande diversidade de cursos de formação e treinamento na atividade turística (STF, 2007). Isso gera recursos humanos de qualidade. Além disso, a mão de obra do turismo nessa nação vem em grande parte do exterior, porque os hotéis não são competitivos no mercado de mão de obra doméstico e a mão de obra nacional não aceita os salários mais baixos do setor turístico nacional (OCDE, 2000). Assim, a Suíça ocupa o quarto lugar no ranking mundial de recursos humanos, o que é apresentado na Tabela 1 acima.

A infraestrutura, por outro lado, também é um ponto importante para determinar a competitividade de um país no turismo. Nesse cenário, é considerada pelo Índice Mundial de Competitividade em Turismo a infraestrutura do transporte aéreo, do transporte público, do turismo e do ICT (internet), nos quais a Suíça encontra-se respectivamente na décima sétima, primeira, sétima e terceira posições, bem a frente do Brasil, que não se encontra nem entre os quarenta primeiros países nessas categorias, o que também é mostrado na Tabela 1.

Dessa maneira, é correto constatar que a Suíça é desenvolvida quando se trata de infraestrutura e as justificativas para isso são muitas. Primeiramente, a Suíça possui uma imensa variedade de meios de transporte, que inclui ônibus, trem, carros particulares, metrô, avião, sendo a proporção de cerca de $20 \%$ de trem, $50 \%$ de carro, $18 \%$ de avião e o restante em ônibus e metrôs quando a viagem é de apenas uma noite (STF, 2007).

Segundo, no caso do transporte aéreo, uma viagem internacional para a Suíça pode ser feita por meio da Swiss/nternational Air Lines, que é a companhia aérea nacional da Suíça e representa os valores tradicionais deste país, sendo conhecida pela qualidade de produto e serviço, com um atendimento personalizado e qualificado (Suíça, 2012b). Os principais 
aeroportos do país são os de Zurique, Genebra, Berna, Engadin e da Basiléia (Suíça, 2012f) e em 2006 eles registraram mais de 620000 embarques e desembarques e 33,5 milhões de passageiros, dos quais $18 \%$ ( 6 milhões) estavam utilizando a Suíça como ponto de passagem (STF, 2007).

No transporte público e terrestre, a Suíça é a mais bem colocada no ranking devido à qualidade de suas estradas, ferrovias e portos (WEF, 2009). Isso está retratado na Tabela 1, que mostra que a pontuação do país nesse quesito é bem elevada: 6,58. Devido a sua localização estratégica na Europa, a Suíça possui serviços rápidos, de qualidade e confiáveis de transporte ferroviário intereuropeus de pelo menos uma dúzia de países, entre eles Alemanha, Itália, Áustria, Espanha, França, República Checa, Hungria (Suíça, 2012e). A rede ferroviária do país se estende por 5270 quilômetros e é uma das mais densas do mundo, tendo transportado 285 milhões de passageiros somente nas ferrovias de posse do governo (STF, 2007), o que mostra a qualidade dessa rede. Para os turistas que optarem chegar por via rodoviária, à Suíça está conectada a extensa rede europeia de autoestrada (Suíça, 2012d). Ainda há a alternativa de transporte por meio da navegação nos lagos suíços, nos quais existem 26 companhias num total de 22 lagos e onde foram transportados mais de 13 milhões de pessoas em 2005(STF, 2007).

Já a infraestrutura do turismo na Suíça envolve principalmente os hotéis (WEF, 2009). Deles, pode-se afirmar que embora o número de hotéis cadastrados e quartos disponíveis tenham caído nos últimos anos devido à crise econômica e financeira e a força da moeda suíça, o país ainda é um destino atrativo e com uma forte reputação no turismo (Tajeddini, 2011).

Outro fator que colabora para o grande desenvolvimento e atratividade do setor é a segurança e seguridade, pois a Suíça sempre foi uma terra neutra em guerras e não é um país que vive a instabilidade de atentados terroristas. Por isso, o país ocupa a oitava posição no ranking nesse quesito, enquanto o Brasil não está entre os cem mais bem colocados, o que indica que esse fator é preocupante no Brasil (WEF, 2009).

Entretanto, apesar do elevado crescimento do setor, o turismo na Suíça ainda possui potencial para se desenvolver cada vez mais, mas isso depende da ajuda de uma política cuidadosamente direcionada para o crescimento e o emprego nesse setor (OCDE, 2000).

Cabe destacar que a política econômica ressurgiu com a competição mundial entre as diversas localidades, sendo hoje ligada a questões como oferecer investidores as melhores condições para competir por fatores de produção escassos, o que envolve taxas mais favoráveis, recursos humanos qualificados e infraestrutura, e voltada para o desenvolvimento. Em vista dessa nova política econômica, a política do turismo na Suíça passou a ser defendida por vários grupos políticos importantes, também a ser baseada em artigos da Constituição Federal relativo à economia e, finalmente, a ser orientada para o desenvolvimento (OCDE, 2000).

O objetivo principal da política do turismo suíço é alcançar alto valor agregado com o fluxo menor possível de visitantes, ou seja, o setor tem que crescer qualitativamente devido ao seu tamanho. Assim sendo, pode-se assinalar que como o país tem seu desenvolvimento quantitativo no setor limitado pelo seu tamanho, a política de turismo da Suíça é voltada para a diferenciação e 
marketing direcionado e centralizado, baseado em uma única marca: a "Suíça" (OCDE, 2000). Um conceito de marca clara e credível é necessário para uma percepção positiva sustentada da Suíça, permitindo que ela se diferencie internacionalmente (Image Switzerland, 2012).

Outro movimento que ganha força nas políticas turísticas suíças é aquele que busca a cooperação entre empresas, setores e organizações de turismo para obter economias de escala, aumentar a sinergias e reduzir de custos de organização (OCDE, 2000). O país ainda possui política de uma educação voltada ao turismo, que é uma marca da Suíça (Weiemair \& Bieger, 2005). O país introduziu, por exemplo, cursos de formação na indústria hoteleira e de restauração (STF, 2007).

Contudo, muitas vezes as ações estatais tem mais impacto no setor turístico do país do que políticas diretas, como quando o estado atua como coprodutor e fornece serviços, aumentando a competitividade do turismo. Também são exemplos as ferrovias subsidiadas pelo Estado e a atual transição da Suíça da agricultura intensiva apoiada por preços de venda garantidos pelo Estado para uma maneira de gestão da terra fundamentada em subsídios fornecidos com base em critérios ecológicos, ajudando a manter a "paisagem cultural" do país (OCDE, 2000). Este último exemplo é a confirmação que a Suíça tem uma legislação que foca a sustentabilidade, como já foi dito anteriormente. Em diferentes termos, a consciência pública sobre a necessidade de manter as paisagens e proteger o meio ambiente na Suíça é altamente desenvolvida (OCDE, 2000).

Enfim, a política de turismo nessa nação é bastante antiga, caracterizada por diversas leis, não é determinada em um único nível e o governo federal e suas instituições possuem um papel cada vez mais importante na área de gestão estratégica dela. No entanto, o setor turístico ainda é pouco subsidiado pelo governo (quase $0,1 \%$ do orçamento total), pode ser ainda muito explorado por meio de políticas governamentais e sofre dificuldades para recrutar mão de obra qualificada devido ao salário baixo que é pago, o que também pode ser mais enfatizado pelas políticas (OCDE, 2000).

Com essas características, a Suíça fica na décima oitava posição quando se considera o fator de competitividade do turismo de regulamentações e leis políticas, enquanto o Brasil aparece apenas quando se observa o top 100 do Índice de Competitividade. Percebe-se que a Suíça é bem desenvolvida nesse setor em relação ao Brasil, mas existem outros fatores nos quais ela se destaca muito mais, como recursos naturais, infraestrutura de transporte público, segurança e sustentabilidade.

Apesar de não estar entre os dez primeiros países colocados quanto às políticas, provavelmente o grande problema da Suíça não seja esse. O que diminui realmente a competitividade dessa nação é o preço, categoria na qual o país não está nem entre os 100 países mais competitivos do mundo segundo o Índice Mundial de Competitividade no Turismo (WEF, 2009). É verdade, que com exceção da Espanha, as nações europeias não são muito caras para o visitante (Dwyer, Forsyth \& Rao, 2000), porém, os gastos do turista são particularmente altos na Suíça, o que é um reflexo da natureza dos bens e serviços fornecidos, que são caros e de 
qualidade (OCDE, 2000). O preço alto dos bens e serviços turísticos ocorre devido aos altos salários, que fazem com que as médias e pequenas empresas tenham que compensar a baixa produtividade elevando os preços e reduzindo a competitividade internacional no setor (OCDE, 2000).

Sobre a Suíça, pode-se então concluir que o alto nível de valor adicionado pela sua indústria turística pode ser explicado pelo fato do país ter se especializado no setor por mais de um século (OCDE, 2000). Dessa forma, o país criou diversas fontes de competitividade e atratividade no setor, como uma política voltada para o desenvolvimento sustentável no turismo, uma infraestrutura aérea, pública e de turismo muito boa e uma imagem de nação segura e que investe e prioriza o setor. No entanto, essa nação ainda tem um ponto fraco evidente no turismo: o elevado preço.

\section{COMPETITIVIDADE DO TURISMO NO BRASIL}

O Brasil é um país de dimensões continentais, com um grande potencial e condições para o desenvolvimento de qualquer atividade, entre elas o turismo. Nos últimos tempos, esse setor voltou a ser o foco do governo nacional devido a dois grandes eventos que o Brasil sediará nos próximos anos: a Copa do Mundo de 2014 e as Olimpíadas de 2016.

Como já foi dito, no caso da Copa, o governo federal passou a realizar grandes investimentos, implantar políticas, ações e projetos no setor do turismo, juntamente com o Ministério do Turismo. Isso ocorreu, pois o governo nacional reconheceu no evento uma oportunidade de desenvolvimento local e nacional de forma sustentável dos destinos turísticos escolhidos como sede, por meio da estruturação dessas localidades, para que estas atinjam um padrão de qualidade internacional e estimulem a permanência do turista antes, durante e depois do evento, e se tornem fontes de renda e emprego para a população brasileira (Brasil, 2011).

As políticas e ações do governo voltadas ao turismo e a priorização do setor são recentes no Brasil. No cenário político, o país quando comparado a outras nações, teve suas primeiras regulamentações turísticas somente em 1958, ligadas fundamentalmente à energia e aos transportes (Becker, 2001). A primeira conquista relevante em termos de implementação de políticas públicas para o turismo brasileiro ocorreu apenas na década de 1990, com a criação do o primeiro planejamento estratégico do turismo no Brasil, a chamada "Política Nacional de Turismo" (Lopes, 2006). Esse planejamento foi elaborado pela EMBRATUR, que estabeleceu as principais estratégias, diretrizes e programas da atividade turística no período (Lopes, 2006).

Enquanto esses avanços políticos começam a ocorrer no Brasil, a Suíça desenvolve o setor há mais de um século e possui muitas políticas voltadas para a sustentabilidade. No entanto, apesar desse aspecto ser incipiente no Brasil, é importante continuar a implantar políticas e programas para o desenvolvimento desse setor tendo em vista a grande capacidade desse segmento de gerar novos empregos, o que é uma preocupação no Brasil (Casimiro Filho, 1999). É necessário avançar em relação ao desenvolvimento das políticas públicas no turismo, sobretudo 
aquelas ancoradas em pilares como sustentabilidade, educação e capacitação profissional (Lopes, 2006). O governo deve, por meio das políticas públicas, estimular o desenvolvimento adequado do setor concomitante ao equilíbrio das funções públicas e privadas, porque a competição entre as nações mundialmente é cada vez mais acirrada (Knupp et al., 2012).

Quanto à priorização do turismo, pode-se dizer que isso passou a ocorrer efetivamente a partir do primeiro mandato do Presidente Fernando Henrique Cardoso, no qual o turismo já fazia parte da "Proposta de Governo", e passou a ser considerada atividade fundamental para o desenvolvimento econômico e social do Brasil (Lopes, 2006). Outra maneira de ver que priorizar esse setor no país é algo novo é observar que a criação de um Ministério de Turismo aconteceu apenas durante o governo Lula, em 2003, pois nesse momento foi entendido que esse é um setor que requer um maior montante de investimento, mas apresenta os melhores resultados (Catrambye \& Costa, 2004). É por isso então que o Brasil ocupa respectivamente apenas a nonagésima quarta posição e a octogésima quarta posição nos fatores de regulamentações e leis políticas e de priorização do turismo do TTCl (muito atrás da Suíça nesses dois pontos), como é possível observar na Tabela 1.

Retomando um pouco a questão das políticas públicas e aprofundando um pouco a questão de desenvolver e renovar estas políticas brasileiras no turismo, surge o elemento de sustentabilidade como fator a ser incorporado a elas e a ser analisado como medida do desempenho turístico do país (Knupp et al., 2012). Segundo a Tabela 1, nesse quesito de competitividade, o Brasil ocupa apenas o trigésimo terceiro lugar no ranking, com 4,96 pontos, bem atrasado em relação à Suíça (segunda colocada mundialmente).

Um dos principais motivos para essa distância no ranking entre o Brasil e o país europeu pode estar ligado justamente às ações políticas sustentáveis já presentes no governo suíço enquanto que no Brasil essas ações e políticas ainda estão em fase de desenvolvimento e renovação. Contudo, não se pode falar de turismo sustentável no Brasil sem mencionar o ecoturismo, que está em desenvolvimento no país e envolve uma utilização controlada das áreas turísticas com planejamento de uso sustentável de recursos naturais e culturais (Beni, 2001).

Além do quadro político, o Brasil possui características preocupantes quanto a outros fatores que geram vantagem competitiva no setor como o transporte, que permanece subdesenvolvido, com baixa qualidade em estradas, aeroportos, ferrovias e portos e como a segurança, que continua sendo uma grande preocupação no país (WEF, 2009).

No caso dos transportes e sua infraestrutura, "faltam linhas aéreas, contêineres, há excessivo gasto no deslocamento da produção, há perdas ocorridas por avarias no transporte, além de existir a distorção da matriz de transportes, havendo uma sobrecarga do modal rodoviário" (Ehrhart \& Palmeira, 2006, p.2). Mais detalhadamente, de acordo com a Tabela 1, a infraestrutura de transporte aéreo do Brasil está apenas entre os 46 países mais bem colocados nesse ponto mundialmente, diferente da Suíça que está dentro do top 20 no ranking desse contexto.

A justificativa para essa posição nacional inferior é que o Brasil, além de possuir uma situação econômica que vem sendo desfavorável às transportadoras aéreas, tem um custo 
muito alto para que essas se mantenham (juros altos, variações no câmbio, altos preços de combustíveis), desfavorecendo as companhias nacionais em um ambiente de competição internacional (Marchetti et al., 2011). Entretanto, mesmo com uma provável diminuição nos custos, é difícil competir com as companhias americanas e europeias, que possuem porte, escala e tamanho maior que das brasileiras (Marchetti et al., 2011).

Pode-se dizer que a pouca utilização e desenvolvimento do modal aéreo no Brasil podem estar conectados principalmente com o fato das tarifas serem muito altas, diferentemente de países de primeiro mundo que tem uma política de tarifação adequada (Ehrhart \& Palmeira, 2006). Convém lembrar que o transporte aéreo é um ponto crítico para a competitividade turística do Brasil desde 2001, o que vale até hoje, mas essa área necessita de um planejamento de médio e longo prazo mais elaborado do governo para que esse modal cresça (Knupp et al., 2012).

Porém, a infraestrutura precária do transporte aéreo e dos aeroportos é um problema de menor expressão no turismo do Brasil se comparado à infraestrutura de transporte público (sobretudo terrestre), na qual, pela Tabela 1 percebe-se um verdadeiro abismo entre Brasil e Suíça. Enquanto o primeiro ocupa a posição de número 110 no $\mathrm{TTCl}$, o segundo é o país mais desenvolvido nesse aspecto. Isso ocorre devido aos inúmeros problemas que existem nos modais de transporte e sua estrutura no Brasil. A malha rodoviária, por exemplo, que representava já em 2006 quase 60\% do transporte nacional, tem estradas e rodovias em péssimo estado (devido ao alto custo de manutenção) e que não recebem investimentos em proporções adequadas (Ehrhart \& Palmeira, 2006). Nessa grande utilização de rodovias, o meio de transporte que prevalece no Brasil para o turismo é o ônibus, que reduz o custo de viagem, enquanto para os europeus é o trem (Beni, 1997).

A malha férrea, tão importante e desenvolvida para os europeus, é pequena no Brasil e atinge apenas pontos isolados do território nacional (Ehrhart \& Palmeira, 2006). Nesse tipo de transporte, o Brasil enfrenta dois grandes problemas para o desenvolvimento: (1) o país não tem tradição alguma quanto ao uso do trem como transporte turístico, e toda política nacional de transporte de massa é voltada para o modal rodoviário e a indústria automobilística e; (2) a rede ferroviária nacional não foi sensível ao utilizar o trem como transporte para o turismo de massa (Beni, 1997). No entanto, "o modal ferroviário deveria ter maior atenção por parte do Governo, pois é o que possui um dos menores custos para o transporte de mercadorias e poderia aumentar o nível de competitividade do Brasil" (Ehrhart \& Palmeira, 2006, p.5).

Já o modal aquaviário, que inclui os portos e sua qualidade, mas no Brasil inclui principalmente o transporte hidroviário, requer maiores cuidados. $O$ setor tem um desenvolvimento lento em comparação a outros países, apesar de transportar grandes volumes e escoar produções agrícolas de grande porte (Ehrhart \& Palmeira, 2006).

"Em termos regionais, o norte e nordeste brasileiros apresentam infraestruturas de acesso e recepção extremamente precárias, enquanto as regiões Sul, Sudeste e Centro Oeste apresentam indicadores de melhor qualidade" (Brasil, 2009a, p. 106). Todavia, em termos gerais, a infraestrutura de transportes nacional ainda está muito atrasada e pouco desenvolvida em 
relação aos outros países. O Brasil precisa investir muito em infraestrutura e crescer muito nesse aspecto para conseguir diminuir custos e competir internacionalmente no turismo nesse ponto, gerando um maior desenvolvimento econômico. Esse desenvolvimento é possível, principalmente no setor aéreo, pois se percebe nele um grande potencial dentro Brasil, tendo em vista o conjunto de obras feitas e em efetivação pela Infraero, empresa que controla os principais aeroportos do país e quase a totalidade dos fluxos aéreos nacionais e internacionais no Brasil (Brasil, 2009a).

Entretanto, além da infraestrutura dos transportes aéreo e público, há a infraestrutura do turismo e do "ICT" (internet, telefone), na qual, de acordo com a Tabela 1, o Brasil ainda está apenas nas posições de número 45 e 60 respectivamente no ranking mundial de competitividade em turismo, mas vem crescendo. No caso do segundo fator, o crescimento pode ser visualizado por meio da quantidade maior de sites no Brasil voltados ao turismo e a sua segmentação, principalmente aqueles voltados ao ecoturismo (Beni, 2001). No entanto, as maiores reclamações dos turistas internacionais dizem respeito à telefonia e internet, logo, esse fator tem muito a melhorar ainda (Brasil, 2009c). No caso do primeiro fator, o desenvolvimento fica evidenciado pelo aumento gradativo da competitividade internacional das grandes cadeias hoteleiras nacionais (Saab \& Daemon, 2001).

A infraestrutura de turismo no Brasil deve ser observada com maior cuidado, destacando-se a importância do segmento de hotelaria no desenvolvimento do país. Este, por sua vez, registrou no Brasil a partir da estabilização da economia do país, uma forte expansão da oferta hoteleira, com um aumento de investimentos, sobretudo em hotéis de médio porte e de qualidade, com a sofisticação dos hotéis localizados nas proximidades dos principais aeroportos, com incrementos no setor de eventos com mais feiras e congressos internacionais, com um número maior de flats, entre outros (Saab \& Daemon, 2001). No entanto, apesar do crescimento dessa infraestrutura, o Brasil ainda está em desvantagem em relação aos outros países do mundo, principalmente os europeus.

Outro tema extremamente crítico quando se trata de turismo nacional é a segurança. É nesse contexto de competitividade que o Brasil apresenta o seu pior desempenho no ranking mundial de competitividade em turismo, a posição de número 130 , um total de 122 posições atrás da Suíça (bem desenvolvida nesse aspecto), o que pode ser notado na Tabela 1. A segurança no Brasil sempre foi preocupante. Em 1990, o Brasil representava apenas 0,24\% do fluxo total de turismo no mundo, participando com 0,57 da receita mundial do turismo. Isso era devido em parte à crise brasileira, mas fundamentalmente devido à perda de competitividade e ao forte impacto negativo causado pela deterioração da imagem do Brasil no setor turístico, particularmente de seu "portal de entrada", a cidade do Rio de Janeiro, devido à questão de segurança (Becker, 2001). Numa pesquisa realizada pela EMBRATUR em 1997, constatou-se que o grau de insatisfação de turistas estrangeiros em visita ao Brasil era decorrente de vários fatores, entre os quais estava a segurança pública, com um dos mais significativos percentuais: 13,1\% (Saab, 1999). Contudo, em 2011, a própria EMBRATUR divulgou que a segurança não está 
mais entre as grandes preocupações dos turistas estrangeiros que visitam o Brasil. Mesmo assim, o país ainda precisa evoluir muito nesse quesito.

Cabe assinalar aqui, que além da segurança e infraestrutura, outro ponto que o Brasil precisa melhorar é a questão da afinidade pelo turismo e viagem, no qual o país não ocupa uma posição nem no top 100 do ranking. Esse dado decorre fundamentalmente da questão da abertura do país ao turismo, um dos componentes desse contexto da afinidade com o turismo (WEF, 2009). A abertura econômica dos países ao turismo já é uma realidade, porém para isso ser vantajoso no país, o Brasil precisa ter uma economia nacional eficiente, uma infraestrutura adequada e ter processos menos burocráticos, dando assim uma capacidade de competição maior (Ehrhart \& Palmeira, 2006).

A questão da saúde e a higiene, assim como os outros assuntos citados anteriormente, também é um ponto fraco no turismo brasileiro, que está, de acordo com a Tabela 1, na octogésima posição no $\mathrm{TTCl}$ em relação a esse contexto, enquanto a Suíça está na décima terceira posição. Ela envolve questões de água potável e saneamento, e um sistema de saúde eficiente, o que no Brasil não é uma realidade. Por exemplo, quando se refere à água potável e encanada, saneamento, muitos estados brasileiros ainda possuem uma capacitação baixíssima na questão do acesso (Brasil, 2009a).

Apesar dos inúmeros pontos fracos ou inexplorados apontados no turismo brasileiro, o país possui grandes fontes de vantagem competitiva no turismo. Talvez entre elas, o maior destaque sejam os recursos naturais e culturais (WEF, 2009). Devido à sua extensão territorial, o Brasil possui diversos ecossistemas com elevado grau de atratividade ao desenvolvimento da atividade turística, cujos principais são: a Floresta Amazônica, o Cerrado, a Mata Atlântica, o Pantanal, a Caatinga, a Floresta de Araucária, os Campos do Sul, os Manguezais, e as Zonas costeiras e insulares (Brasil, 2009d). O país ainda tem diversas áreas protegidas por lei, nas quais ocorre o desenvolvimento do denominado ecoturismo e nas quais existe uma grande diversidade, muitas vezes com a presença de espécies em extinção (Brasil, 2009d). Além disso, "distribuída pelo território brasileiro, encontra-se a maior diversidade de vida do planeta. Aproximadamente $2 \%$ das espécies existentes estão presentes no Brasil." (Brasil, 2009d, p.89).

Todas essas informações mostram o motivo pelo qual o Brasil ocupa a segunda posição mundial no TTCl no critério de recursos naturais, como indicado na Tabela 1. Porém, mesmo considerando esse aspecto positivo, vale apontar que os países europeus, como por exemplo, a Suíça, possuem recursos naturais limitados comparados à exuberância tropical brasileira, mas captam fluxos turísticos muito maiores que o Brasil (Beni, 1997). Isso significa que recursos naturais em abundância não garantem vantagem competitiva no turismo, desenvolvimento nessa atividade e desenvolvimento econômico nacional, e, portanto, não garantem o Brasil entre os melhores países no TTCI, no qual o Brasil ocupa a 45a posição no geral.

Os recursos culturais também são um ponto forte do turismo brasileiro, mesmo o país estando atrás da Suíça nesse setor em 11 posições (o Brasil permanece na décima quarta posição no TTCI). A pluralidade, expressão e força cultural do Brasil podem ser vistas pelo 
número de festas populares, feiras internacionais, patrimônios históricos, estádios, entre outros recursos culturais. Nas festas populares se destacam o Carnaval, a Festa de Reis, a Festa do Padroeiro (Padre Cícero), a Festa do Divino, a Festa do Círio de Nazaré, que ocorrem devido a uma sucessão de motivos religiosos ou pagãos, cristãos ou indígenas, de origem europeia ou africana (Biblioteca SEBRAE, 2012). O Brasil possui ainda o Museu Histórico Nacional, o Museu do Marajó, a Fundação Casa de Jorge Amado, a Defesa do Patrimônio Público, o Instituto Estadual do Patrimônio Histórico e Artístico de Minas Gerais (IEPHA) e a Feira Internacional da Amazônia (FIAM), entre outros (Visit Brasil, 2012), além de muitos estádios esportivos que estão melhorando sua infraestrutura e a das cidades nas quais eles se localizam para o evento da Copa de 2014, como o Mineirão e o Maracanã (Brasil, 2011).

Esse imenso patrimônio cultural do país é a base para o desenvolvimento do chamado turismo cultural, termo usado para designar um novo tipo de turismo, que não busca somente locais de destino distintos dos seus locais de vida rotineira, mas também viver experiências significativas, entrando em contanto com culturas diferentes das suas (Brasil, 2009c). Este segmento do turismo ainda não é um grande atrativo no Brasil, mas constitui um mercado em expansão, com diversas possibilidades a serem exploradas (Brasil, 2009c).

Há ainda o preço competitivo como outro tema de fundamental na competitividade em turismo. Observando a Tabela 1, compreende-se que o Brasil está à frente da Suíça nesse ponto, mesmo estando somente na posição de 94 no ranking mundial de competitividade no turismo. Isso não quer dizer que o Brasil seja eficiente e com preços acessíveis no turismo, mas que a Suíça é muito inferior a qualquer país nesse aspecto, inclusive ao Brasil.

Por fim, não se fala de turismo sem mencionar os recursos humanos e a sua força dentro desse setor. Com base nos dados da Tabela 1, percebe-se que o Brasil ocupa apenas a posição de número 55, ao mesmo tempo em que a Suíça é quarta colocada. Porém, se comparado na mesma Tabela 1 com outros contextos, como infraestrutura do transporte público, segurança, afinidade com o turismo, preço, percebe-se que esse aspecto tem que melhorar, mas por enquanto não é o mais preocupante em termos nacionais.

Segundo a WTTO, a economia do turismo no Brasil gerou 5.827.720 empregos em 2005, o equivalente a 7,0\% do emprego total e em 2015, este número deve saltar para 7,2\% (Brasil, 2009b). Isso significa que a tendência é os recursos humanos dentro do turismo brasileiro é crescer muito. Além disso, num médio e longo prazo, o efeito positivo do turismo, que abrange a geração de emprego e renda, vai gerar uma redistribuição de verbas, ações de apoio aos pequenos negócios, capacitação profissional, cooperativismo, formalização, infraestrutura pública, educação formal e profissionalização do turismo no Brasil (Brasil, 2009b).

Em resumo, o Brasil é um país afortunado pelos inúmeros recursos naturais e culturais que possui, mas isso não é suficiente para que o país seja desenvolvido no turismo. Apesar da alta qualidade operacional e de planejamento, ainda tem que solucionar questões de infraestrutura, de segurança, e da complexidade relacionada à extensão territorial. Quando se faz uma comparação direta com a Suíça utilizando os fatores do Índice e suas pontuações, além 
de dados do setor, percebe-se que o país só é superior em dois pontos: os recursos culturais e o preço. No entanto, no caso deste último, essa posição deve-se mais aos problemas da Suíça nessa questão do que aos méritos do Brasil. Ainda, pode-se afirmar que quando se consideram os recursos culturais, os dois países são bem próximos, mas nos outros aspectos a Suíça é bem mais desenvolvida, com destaque nas questões de infraestrutura do transporte público, segurança, priorização do setor, afinidade e sustentabilidade.

\section{CONSIDERAÇÕES FINAIS}

O turismo é um dos fenômenos mais significativos, dinâmicos e complexos do mundo contemporâneo, exercendo influência direta no desenvolvimento econômico, social, político e ambiental de diversos países e regiões nele inseridos. O desenvolvimento do setor é grande em termos mundiais, aumentando a concorrência e a competitividade no setor, o que deve ser analisado com atenção pelos governos dos países para que estes possam adquirir a denominada vantagem competitiva em relação às outras nações do mundo.

Entretanto, no Brasil o setor ainda é incipiente e com muitos pontos a serem aprimorados, principalmente se comparado a países como a Suíça, cujo desenvolvimento nesse setor é significativo. Mesmo assim, o turismo é no Brasil uma das áreas mais promissoras e tem um grande potencial a ser desenvolvido, necessitando de novas estratégias, planejamento e uma maior quantidade de fontes de competitividade para que mais turistas sejam atraídos a vir ao país e mais renda e empregos sejam gerados.

Este artigo fez uma comparação direta entre Brasil e Suíça por meio por meio dos fatores de competitividade do setor, determinados pelo Índice Mundial de Competitividade em Turismo, um documento de extrema relevância nesse assunto. Desse estudo, foi possível tirar algumas conclusões. Entre elas, foi plausível afirmar que a Suíça tem um turismo como uma das grandes bases da economia, enquanto no Brasil, o setor nunca foi uma prioridade em relação a outros, como a indústria automobilística, e apenas recentemente que o país passou a direcionar esforços e investimentos para essa área. Adicionalmente, foi possível inferir que mesmo o Brasil tendo um território extenso, incontáveis recursos naturais e culturais e um grande potencial para o desenvolvimento de qualquer atividade, isso não é suficiente para que o país seja mais desenvolvido no turismo do que a Suíça, que mesmo sendo um país menor possui um alto nível de competitividade, vantagem competitiva e valor adicionado na atividade turística. Deste modo, foi confirmado que a Suíça é muito mais desenvolvida no turismo do que o Brasil, que tem muito a melhorar.

Existem verdadeiros abismos entre Brasil e Suíça, principalmente quando se trata de questões como regulamentações e leis políticas; segurança e seguridade; saúde e higiene; infraestrutura de transporte público; priorização e afinidade com o setor. Esses são aspectos nos quais a Suíça é bem mais desenvolvida que o Brasil, com sua imagem de nação segura e que investe e valoriza o setor. Esses são os pontos mais fracos do turismo brasileiro, que devem ser 
corrigidos por meio de estratégias como a construção de uma imagem extremamente positiva do Brasil, a implantação de políticas de turismo principalmente voltadas para a sustentabilidade e para menores tarifas, pelo investimento em novas estradas, portos e meios de transporte de qualidade, como trens.

A Suíça também possui vantagens quanto à sustentabilidade, infraestrutura de transporte aéreo, infraestrutura de turismo, infraestrutura de "ICT", recursos humanos, e recursos culturais. Porém, esse país perde para o Brasil quando se trata de recursos naturais (que o Brasil possui em abundância) e preços competitivos. No caso deste último fator, ambos os países precisam melhorar e muito, mas na Suíça a situação nesse aspecto é bem mais crítica.

Sobre essa comparação direta entre Brasil e Suíça, concluiu-se que existem muitos pontos a serem analisados no turismo brasileiro, que quando comparado ao turismo suíço, tem muitos problemas ainda a serem resolvidos, sobretudo aqueles relacionados à infraestrutura de transporte público e aéreo; às regulamentações e leis políticas; à segurança e seguridade; à saúde e higiene; à infraestrutura de turismo; à priorização e afinidade com o setor. Essas deficiências apresentadas pelo Brasil, se melhoradas, podem constituir oportunidades de o setor adquirir vantagem competitiva e se desenvolver, levando também a um maior desenvolvimento econômico nacional.

Nesse sentido, este artigo mostrou em que aspectos governos e empresas dos dois países podem atuar para que as estratégias corretas sejam elaboradas e realizadas, de modo a proporcionar um maior desenvolvimento do setor turístico e da nação. Quando se trata do Brasil, por exemplo, o governo federal poderia adotar a medida de reduzir as tarifas do setor aéreo por meio de algum decreto ou lei, fortalecendo a indústria nacional, criando vantagem competitiva, melhorando esse fator e gerando valor adicionado ao turismo nacional. Outro aspecto que o governo brasileiro poderia melhorar é o investimento e manutenção nas estradas, buscando verbas e parcerias com empresas privadas.

No longo prazo, o ideal seriam políticas voltadas à sustentabilidade, educação e capacitação profissional para que resultados mais concretos sejam alcançados. Adicionalmente, as empresas brasileiras poderiam passar a investir mais nessa atividade baseadas em novas estratégias, como a segmentação de mercado, na qual a empresa de determinada localidade pode se focar apenas no turismo de negócios ou de lazer ou de saúde, especializando-se assim em um tipo e conseguindo uma vantagem competitiva por diferenciação.

Ao observar a Suíça, cujo grande problema é o preço, o governo poderia tentar subsidiar a produção de alguns produtos pelos fornecedores do setor, reduzindo o custo deles e consequentemente diminuindo os preços finais pagos pelo consumidor, o que agregaria ainda mais competitividade ao turismo suíço, e ao país de maneira geral. Ou ainda considerando essa questão, as empresas (sobretudo as da rede hoteleira) poderiam reduzir um pouco seu lucro sobre os bens e serviços no intuito de atrair bem mais turistas, o que compensaria essa redução.

Cabe ainda assinalar que esse artigo também foi uma forma de trazer um maior questionamento sobre o tema e suas implicações, motivando pesquisadores a se aprofundarem 
neste assunto e assim, obterem outros resultados sobre o setor e seu desenvolvimento. Contudo, houve também limitações, entre as quais, pode-se citar uma análise apenas qualitativa que não enfatiza questões do cenário macroeconômico e não considera a questão cultural. Esta última questão é de fundamental importância nesse setor, pois, por exemplo, o que pode atrair um turista estrangeiro a um país depende muito da formação cultural dele. Além disso, a instalação de um novo hotel, que pode aumentar a concorrência, pode ocorrer mais facilmente em um país do que outro.

Estudos futuros podem tentar abordar uma comparação mais quantitativa entre os países, e também tentar ampliar o foco de análise das questões culturais e individuais de cada país, bem como nas questões macroeconômicas, como juros, inflação, momento de aplicar recursos, ou desenvolver modelos de análise mais completos que incorporem essas questões.

Por fim, apesar das limitações mencionadas, pode-se dizer que o artigo abrange muitos pontos que podem ser utilizados em benefício do setor turístico e do seu crescimento tanto na Suíça quanto no Brasil, possibilitando que os governos dos dois países desenvolvam ações estratégicas, além de gerar uma reflexão teórica para pesquisas na área.

\section{REFERÊNCIAS}

Aulicino, M. P. (1994). Alguns impactos Socioeconômicos da Atividade Turística sobre Municípios Paulistas. (Dissertação de Mestrado). Recuperado de http://www.teses.usp.br/teses/disponiveis/27/27136/tde16082011-123252/

Basel Economics - BAK. Succès et Compétitivité du TourisméAlpin. Recuperado de http://www.bakbasel.ch/downloads/services/reports_studies/2007/200711_seco_execsum_f.pdf Becker, B. K (2001). Políticas e planejamento do turismo no Brasil. Caderno Virtual de Turismo, 1(1), 1-7. Beni, M. C. (2001). Análise Estrutural do Turismo. São Paulo: Senac.

Beni, M. C. (1997). Análise Estrutural do Turismo. São Paulo: Senac.

Biblioteca Sebrae. Recuperado de

http://www.biblioteca.sebrae.com.br/bds/bds.nsf/67C179C0B91FB83A832574C8006DFC29/\$File/Festas\%2 Opopulares.pdf

Brasil. Ministério do Turismo. Proposta estratégica de organização turística da copa do mundo 2014-Brasil. (2011). Brasília, DF: ABRASEL, ANAC, SEBRAE, SENAC. Recuperado de http://www.dadosefatos.turismo.gov.br/dadosefatos/outros_estudos/copa_2014/

Brasil. Ministério do Turismo. Competitividade e infraestrutura. (2009a). Brasília, DF: CGEE, INSTITUTO ASCENDE, UERJ, UNICAMP. Recuperado de

http://www.econeit.org/wp-content/uploads/2012/03/INFRAESTRUTURA.pdf

Brasil. Ministério do Turismo. Mercado de Trabalho na Área de Turismo. (2009b). Brasília, DF: CGEE, INSTITUTO ASCENDE, UERJ, UNICAMP. Recuperado de http://www.turismo.gov.br/export/sites/default/turismo/o_ministerio/publicacoes/downloads_publicacoe s/O_MERCADO_DE_TRABALHO_NA_xREA_DE_TURISMO.pdf

Brasil. Ministério do Turismo. O Turismo Cultural no Brasil. (2009c). Brasília, DF: CGEE, INSTITUTO ASCENDE, UERJ, UNICAMP. Recuperado de http://www.ebah.com.br/content/ABAAABi_AAI/turismo-cultural-no-brasil 
Brasil. Ministério Do Turismo. O Turismo e a Dimensão Ambiental. (2009d). Brasília, DF: CGEE, INSTITUTO ASCENDE, UERJ, UNICAMP. Recuperado de

http://www.turismo.gov.br/export/sites/default/turismo/o_ministerio/publicacoes/downloads_publicacoe s/TURISMO_E_A_DIMENSXO_AMBIENTAL.pdf

Casimiro Filho, F. (1999). Contribuições do turismo à economia brasileira (Tese de Doutorado). Recuperado de http://www.teses.usp.br/teses/disponiveis/11/11132/tde-03022003-162953/

Catrambye,T. C. V., \& Costa, S. R. H. (2004). Qualificação Profissional em Turismo como Fator de Competitividade do Setor. Caderno Virtual de Turismo, 4(3), 26-34.

Clegg, S. R., Hardy, C, \& Nord, W. R. (2004). Handbook de estudos organizacionais. São Paulo: Atlas, 1v.

Cooperbom Turismo (2008). Sustentabilidade ambiental no turismo. Recuperado de

http://cooperbomturismo.blogspot.com.br/2008/03/sustentabilidade-ambiental-no-turismo.html

Dwyer, L., Forsyth, F., Rao, P. (2000). The price competitiveness of travel and tourism: a comparison of 19 destinations. Tourism Management, 21(1), 9-22.

Ehrhart, S., \& Palmeira, E. M. (2006). Análise do setor de transportes. Observatório de la Economía Latinoamericana, 1(71). Recuperado de http://www.eumed.net/cursecon/ecolat/br/06/semp.htm

Ferreira, L. B. (2010). Estratégias de segmentação da hotelaria para o turismo de negócios: um estudo em São Luís (MA) (Dissertação de Mestrado). Recuperado de http://www.teses.usp.br/teses/disponiveis/12/12139/tde-04112010-165809/pt-br.php/

Freitas, H. M. T. de. (2010). Turismo médico: a globalização da saúde (Dissertação de Mestrado). Recuperado de http://repositorioaberto.up.pt/bitstream/10216/26936/2/DissertaoTurismo\%20Mdico\%20\%20A\%20Globalizalo\%20da\%20Sa de.pdf

Hassan, S. S. (2000). Determinants of market competitiveness in an environmentally sustainable tourism industry. Journal of Travel Research, 38, 239-245.

Image Switzerland. Recuperado de http://www.image-switzerland.ch/index.php?id=488\&L=1

Knupp, M. E. C. G., Miranda, R. L. P., Figueiredo, F. C., \& Oliveira, A. L. de (2012). Competitividade das nações: uma análise do Plano Nacional de Turismo no Brasil. Turydes, 5(12), 2- 25. Recuperado de http://www.eumed.net/rev/turydes/12/kmfo.pdf

Lopes, C. H. (2006). Análise dos modelos de planejamento e desenvolvimento turístico propostos pela gestão pública no Brasil. Revista Acadêmica Senac On-line, 1. Recuperado de http://www3.mg.senac.br/Revistasenac/edicoes/edicao1.htm

Marchetti, D. , Souza, M. A. T., Ávila, J. R. G. de, \& Castro, M. S. de (2011). Setor Aéreo (Modal Aéreo II). Informe Infraestrutura, Banco Nacional de Desenvolvimento Econômico e Social - BNDES 42.

Organisation de Coopération et de Développement Economiques/Organization for Economic Co-Operation and Development - OCDE. (2000). Swiss Tourism Policy - A Synthesis. Paris. Recuperado de http://www.oecd.org/cfe/tourism/33649503.pdf

Perch-Nielsen, S., Seasartic, A., \& Stucki, N. (2010). The greenhouse gas intensity of the tourism sector: The case of Switzerland. Environmental Science \& Policy, 13(2), 131-140.

Pike, S. (2008). Destination Marketing: an integrated marketing communication approach. Oxford: Elsevier. Porter, M. E. (1999). Competição: estratégias competitivas essenciais. (6a ed.). Rio de Janeiro: Campus.

Saab, W. G. L., \& Daemon, I. G.(2001). O segmento hoteleiro no Brasil. BNDES Setorial, 1(13), 127-156.

Saab, W. G. L. (1999). Considerações sobre o desenvolvimento do setor de turismo no Brasil. BNDES 
Setorial, 1(10), 285-312.

Serquet, G., \& Rebetez, M. (2011). Relationship between tourism demand in the Swiss Alps and hot summer air temperatures associated with climate change. Climate Change, 10(108), 291-300.

Swiss Tourism in Figures - STF. (2007). Switzerland Tourism. Geneva. Recuperado de http://www.swisstourfed.ch/Files/infothek/Vademecum/2007/Def\%20Version\%20englisch.pdf

Suíça. Site Oficial do Turismo na Suíça. Parques Nacionais \& UNESCO. Zurique, 2012a. Recuperado de http://www.myswitzerland.com/pt/destinos/parques-nacionais-unesco.html

Suíça. Site Oficial do Turismo na Suíça. Swiss International Air Lines. Zurique, 2012b. Recuperado de http://www.myswitzerland.com/pt/footer/footer-links/parceiros/parceiro-comercial/swiss-internationalair-lines.html

Suíça. Site Oficial do Turismo na Suíça. Tradições e Cultura na Suíça. (2012c). Zurique. Recuperado de http://www.myswitzerland.com/pt/sobre-a-suica/tradicoes-e-cultura-na-suica.html

Suíça. Site Oficial do Turismo na Suíça. Viajando para a Suíça de carro. (2012d). Zurique. Recuperado de http://www.myswitzerland.com/pt/transporte-1-1/viajando-para-a-suica/de-carro.html

Suíça. Site Oficial do Turismo na Suíça. Viajando para a Suíça de trem. (2012e). Zurique. Recuperado de http://www.myswitzerland.com/pt/transporte-1-1/viajando-para-a-suica/de-trem-1.html

Suíça. Site Oficial do Turismo na Suíça. Viajando para a Suíça pelo ar. (2012f). Zurique. Recuperado de http://www.myswitzerland.com/pt/transporte-1-1/viajando-para-a-suica/pelo-ar.html

Tajeddini, K. (2010). Effect of customer orientation and entrepreneurial orientation on innovativeness: Evidence from the hotel industry in Switzerland. Tourism Management, 31(2), 221-231.

Tajeddini, K. (2011). Customer orientation, learning orientation, and new service development: an empirical investigation of the Swiss hotel industry. Journal of Hospitality\& Tourism Research, 35(4), 437-468.

Valls, J. F. (1996). Las claves del mercado turístico: cómo competir en el nuevo entorno. Bilbao: Deusto.

Visit Brasil. Recuperado de http://www.visitbrasil.com/about_maisbrasil.html?_locale=pt_BR

World Economic Forum - WEF. The Travel \& Tourism Competitiveness Report 2009: Managing in a Time of Turbulence. (2009). Geneve. Recuperado de http://www.weforum.org/reports/travel-tourismcompetitiveness-report-2009

Weiemair, K.; \& Bieger, T. (2005). Tourism Education in Austria and Switzerland: Past problems and future challenges. Journal of Teaching in Travel and Tourism, 5(1), 39-60.

World Travel \& Tourism Council - WTTC. (2011a). Economic Impact of Travel \& Tourism. Recuperado de http://www.wttc.org/site_media/uploads/downloads/4pp_document_for_WTM_RGB_1.pdf

World Travel \& Tourism Council - WTTC. (2011b). Travel \& Tourism Economic Impact.

Artigo recebido em: 11/12/2012. Artigo aprovado em: 07/03/2013.

'Esta pesquisa contou com o apoio financeiro do CNPq 